\title{
Polymers and Sustainability - an Impossible Combination?
}

Manuscrit reçu le 16 novembre 2020 et accepté le 11 février 2021

Philip B. V. SCHOLTEN

Adolphe Merkle Institute, Chemin des Verdiers 4, 1700 Fribourg

\begin{abstract}
Polymers, known as plastics in everyday life, are essential to our current way of life. Many of the technological advances of the last hundred years were only made possible by these versatile, lightweight and cheap materials. While problems with our current use of this material are evident, this article highlights the advantages of polymers and how they are key to a more sustainable future with a possibly circular economy.
\end{abstract}

\section{Keywords}

Polymers, sustainability, materials, Circular Economy, Green Chemistry

\section{1 - Introduction}

The year, 2020 marks the $100^{\text {th }}$ anniversary of a game-changing theory developed by Hermann Staudinger [1]. Contrary to the previous assumption that molecules cannot be more than a few nanometres $(0.0001 \mathrm{~cm})$ long, Staudinger proposed that molecules can exist in long chains, so-called macromolecules [2]. To visualise this concept, take the elements of a metal chain as an example. By themselves, they are very mobile and are easily deformed if stepped on. However, once they are connected into a long chain, the mobility of the macromolecule and the force that can be applied to it is completely different compared to those of the individual units (Figure 1). This is very similar to the concepts of monomers (from ancient Greek: one part), the individual elements of the chain, and polymers (from ancient Greek: many pieces), the finished chain. Also check out this video (in French) explaining the concepts of polymers during the "My Thesis in 180 Seconds" contest [3].

\footnotetext{
${ }^{*}$ ORCID : 0000-0001-5187-7003
} 


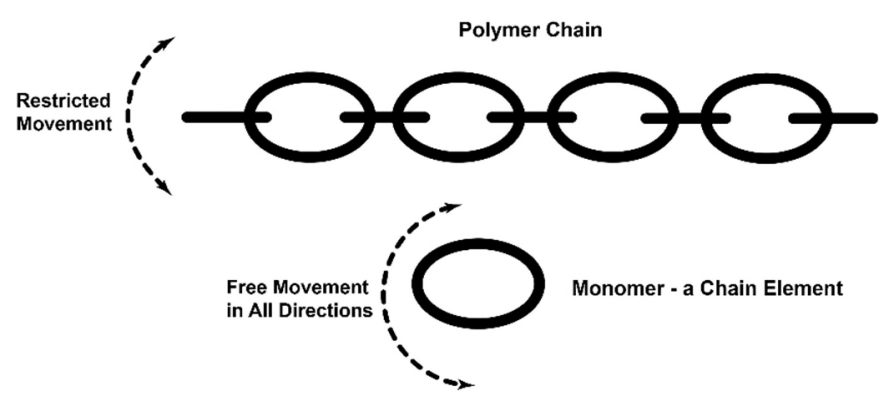

Figure 1: Illustration of the concept of monomers and polymers using a metallic chain as an example.

Since this controversial theory, macromolecules (also called plastics), have seen an incredible development and are taken for granted in our daily lives. Take the laptop on which you might be reading this article, for example. Apart from the visible plastic parts, such as the outside casing, screen, keyboard, and charger, hidden inside are various elements composed of plastic. Every cable within the computer has a polymer casing to insulate it from its surroundings. Additionally, the glue used to hold various components together is a polymer. Without polymers, you would not be able to read this article on your laptop or any other electronic device you own. The term "polymer" encompasses far more materials than those typically associated with the term "plastic", i.e. plastic bags and packaging. The reason for this versatility is the basic structure of polymers themselves; the overall properties of the polymer chain can be easily altered by either using a different monomer, like changing the shape each link in the chain, or by combining different monomers with contrasting characteristics. A powerful example of this is polyethylene (PE), which is made up of individual ethylene units. If it is made in a specific way, it is the extremely stiff material used for bottle caps. However, if another monomer (e.g.: hexene) is incorporated and the processing is slightly altered, it is stretchable and can be used as a classic plastic shopping bag. While this example clearly highlights how easily the properties of a polymer can be altered, it brings me to the core of this article, which is the environmental concerns associated with plastic waste and how we can make polymers more sustainable and better for the environment. While there are undeniable problems with plastic waste accumulating in the environment, a call for a future without plastic is not only impossible if we want to keep our current living standards, but also short-sighted in the context of sustainability. The following sections try to highlight these aspects and give a strategy I envision for how we can overcome the current plastic problems. 


\section{2 - Why we need polymers for a sustainable future}

Let's start with a question often heard by polymer scientists: why do we rely on plastics and don't simply return to using glass, steel, wood and paper as materials in light of the current plastic pollution? These traditional materials are simply not able to perform many of the tasks for which polymers are (would a heavy steel laptop casing really be practical?), but the less intuitive answer is that polymers generally consume less energy and resources during their production than these materials and enable resource conservation in their application.

An example we encounter every day is the use of polymer films to cover meat, vegetables and other food. These films are extremely thin (around $0.012 \mathrm{~cm}$ ) and protect the food from oxygen, bacteria, and pathogens, amongst other possible contaminants [4]. Without these protective layers, we would not be able to store food as long as we currently do, which would lead to a massive increase in food waste. In addition, significant progress has been made in reducing the amount of polymer film needed, either by reducing the thickness of the film itself or using multiple layers of different polymers to fully protect the food.

A powerful example highlighting the increased energy and resource consumption and decreased sustainability of traditional materials compared to polymers is that of the shopping bag. A study in the United Kingdom in 2011 analysed the overall life cycle of cotton, plastic, and paper shopping bags [5]. A method called Life Cycle Assessment (LCA) was used, which is one of the best ways to calculate and compare the environmental impact (toxicity of chemicals, consumption of energy and water, $\mathrm{CO}_{2}$ generation, etc.) of products during each stage of their life, i.e. production, transportation, use, and end-of-life [6,7]. Counterintuitively, the study found that a paper bag has to be reused at least 3 times in order to reduce its overall environmental impact to below those of conventional, thin plastic shopping bags. While reusing is not an issue for plastic bags since they can be easily reused for shopping or as a bin bag, a paper bag tears much more easily and is not reusable if it gets wet. As a result, using a paper bag more than once is much more challenging than reusing a plastic bag. Even more interestingly, a cotton bag would have to be reused 131 times before it is more environmentally-friendly than a plastic bag. This case study highlights the complexity of a product's environmental impact and the fact that polymers can be the solution to a more sustainable future, if used correctly. This latter point is key, as the study assumes that all plastic bags are either burned or put into landfills at the end of their use. While this may certainly apply to the majority of plastic bags in the UK, the waste collection system of many countries is not as evolved, leading to plastic bags being disposed of in the environment - one 
of the key issues with plastic waste. So, how can we avoid this problem of plastic waste accumulation? One very promising answer is by changing the way we design, use, and dispose of products to move towards a closed loop of raw materials and resources, a concept often referred to as a Circular Economy [8,9].

\section{3 - A circular economy - the way forward}

The concept of a Circular Economy relies on the idea that the majority of our resources and energy are renewable, i.e. not finite, and their use happens in continuous loops with minimal losses throughout all stages of a product's lifetime (Figure 2). This is contrary to our current way of using products, which is very linear: make, use, dispose - with very limited reuse and recycling happening. Part of the issue is the continued drive for growth and increase of product sales, leading to the planned obsolescence and programmed breakage, of products in order to stimulate the purchase of a new product. The discussion of this very philosophical aspect is outside of the scope of this article, but the bottom line remains; products need to be sold to generate income. The fate of the products after the end of use is generally neglected in the product design and left to the consumer and local infrastructure to deal with. This linear thought process has led to a transfer of raw materials into waste, which is now accumulating. Much of this waste is not recyclable composed of different, difficult-to-separate materials, non-reusable, and leads to a growth of waste in landfills or the environment. This problem not only applies to packaging and plastics in general [10], but also to electronic equipment [11].

A circular economy tries to circumvent the issue of waste by considering the whole lifecycle of a product during its design stage, attempting to ensure the reuse, upcycling, and recycling (see below) of all products. This complete consideration of a product is extremely complex and requires the expertise of many players in order to bring it to a success. At the core of this approach is the renewability of energy and raw materials. Renewable energy, in particular, has received increasing attention from governments, scientists, and the general public as a result of the global challenge of climate change.[13] Currently, the majority of energy used originates from fossil fuels [14], a finite resource that is burned to obtain energy, consequently releasing $\mathrm{CO}_{2}$ and other gases such as nitroxides. While it is still unknown how long this energy source will last, it is certain that we will run out of it eventually. In addition, considerations such as dependence on certain countries exporting fossil fuel has driven 


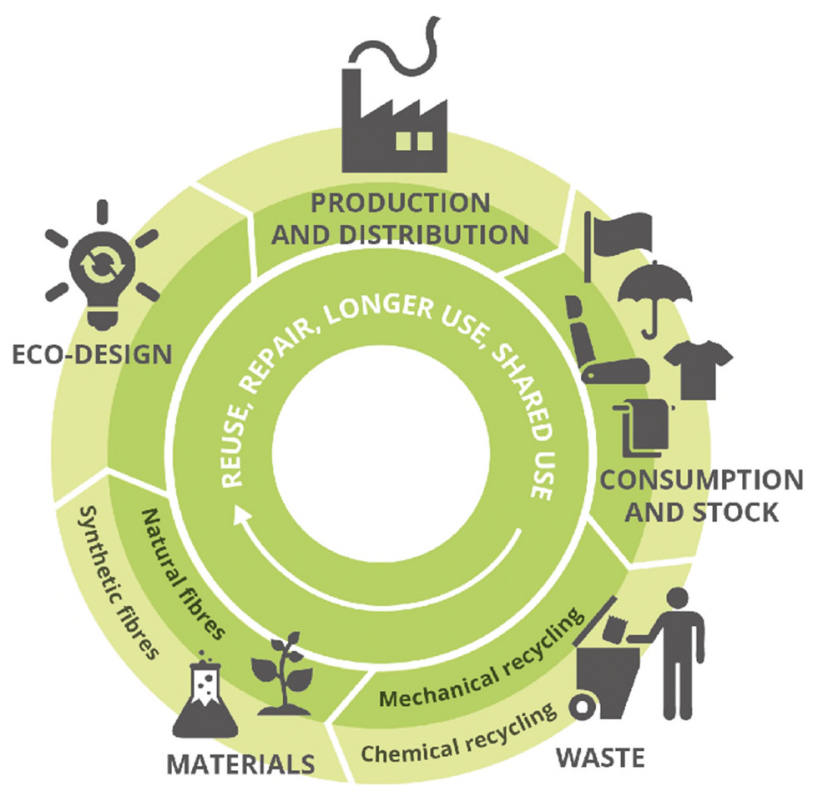

Figure 2: Schematic representation of the circular and closed flow of resources and energy as proposed in a circular economy. Image taken from the European Environment Agency [12].

innovation and investment into the collection of energy from renewable sources, such as light and water. While renewable sources of energy provide the power to produce products from raw materials, the origin of these raw materials is equally as important in a circular economy. Apart from fossil fuel used for energy, other resources, such as metals, are finite and not available renewably. This means if we keep mining and using these for our technological products, we will run out at some point. The European Union publishes a list with elements of the periodic table which it considers to be key to our economy but are either only poorly available in natural rocks or unavailable because of other reasons, such as politics or conflicts [15]. Many of these can be found in consumer products including smartphones, laptops, washing machines, and cars, so restricted access to such elements would lead to an increase in prices. It is therefore vital that efficient recycling strategies are put into place (see below) so that a loss of these precious elements is reduced if not stopped altogether. As stated previously, this requires the combined effort of many different disciplines to manage the creation and execution of detailed plans throughout a product's lifespan.

Changes are already visible in the private sector, where a few companies have been founded around a sustainable product, in line with a circular economy. Examples can be found in the fashion, furniture and smartphone sector. Established companies have also had to rethink their operating principles, leading to some altered business practices. One way of doing this is, adopting a more service-oriented approach: instead of selling a product to a costumer and 
that's it, selling the product and the upkeep, servicing and replacement of this product throughout its lifespan. This ensures that the company develops products which are longlasting, as otherwise it has to pay for their replacement, and that the product works as efficiently as possible to prevent the costumer from looking for alternatives. Apart from activity in the private sector, governing bodies have also developed roadmaps to move towards a more sustainable and possibly circular future. Examples include the EU action plan for a circular economy [16] and the UN sustainability goals [17]. Most important, however, is citizens' realisation that one's own adoption of a sustainable life is equally as important as more global changes. Only jointly will such a radical and complex transition become a reality.

\section{4 - Recycling is key}

The biggest unsolved problem of plastics is that their recycling is not as straightforward as traditional materials such as glass or steel. While glass, aluminium, or steel are simply melted at very high temperatures $\left(>500^{\circ} \mathrm{C}\right)$, at which all remaining impurities from their use are burned away, polymers cannot be heated so high because they themselves would be burned and start degrading. For example, the melting temperature for polyethylene, which is used as bags or films in packaging, is around $120{ }^{\circ} \mathrm{C}$. At this temperature, most organisms are destroyed, but other impurities are not. Consider the recycling of two bottles, both made from polyethylene, one containing engine oil and the other containing milk. In an ideal scenario, these will be collected, melted at $180-200{ }^{\circ} \mathrm{C}$, and shaped into new bottles, which again will be used for milk and engine oil. In both cases, however, the remaining milk and oil traces left at the end of their use mean that, without a cleaning step, these end up in the future bottles, posing serious health risks. Who would want engine oil in their milk for breakfast? Therefore, the collected plastic waste needs to be thoroughly cleaned and all impurities from their previous lifetime need to be removed. This not only complicates the recycling process, but also makes it much more expensive and time-consuming, and thus economically uninteresting. Further complications also arise from the fact that there are many different types of plastics, and their joint recycling is not possible because of a mismatch in their properties. As a result, the different types of plastics have to be separated and recycled individually. This drastically increases the price of such recycled materials and again makes it unattractive for companies trying to gain as much money as possible.

Nonetheless, innovative strategies have been developed to overcome this recycling problem, and some have already been put into action. The most successful example is the recycling of 
poly(ethylene terephthalate), PET, which is mainly used for drink bottles. In 2017 58\% of PET resin was recycled in the EU, amounting to close to 2 million tons of PET [18]. This recycled PET can be reused to make new drink bottles or be upcycled to T-shirts, carpets or fleece sweatshirts amongst others. Other, recent approaches use chemical or advanced recycling [19-21]. This process consists of breaking the polymer chain into its original, basic units by chemical processes and reusing these units to make the same or a similar polymer. The advantage of this strategy is that the purity of the obtained building blocks is ensured, the disadvantage is that this strategy only works for certain polymers and is not a universal recycling solution. Overall, both traditional and chemical recycling are useful pathways to reuse existing raw materials for new applications. Through consumer demand and continued pressure from governments and legislation to increase the amount of recycled plastic in circulation, the current recycling challenges will be overcome and a more circular flow of plastics ensured.

\section{5 - Degradable Plastics}

An alternative to recycling is to make polymers inherently degradable. This concept is often perceived as the solution in the public eye, but there are a few misconceptions around this topic. First of all, degradation does not mean biodegradation: just because a polymer degrades under certain conditions, such as an industrial composting with elevated temperatures and specific microbes, does not mean it will degrade in the environment, on the side of the road or in the ocean. The degradation process of a polymer is very complex and depends on many aspects, such as the surrounding materials, temperature, and humidity. In addition, the timeframes at which degradable polymers decompose can also span several years, during which they are still present as plastic waste, in the worst case scattered in the environment. Once these polymers are degraded into smaller bits, it is important that these micro- or nanoplastics can also be further degraded by natural organisms within a reasonable timeframe and that the degradation products are not toxic or harmful to the environment. An example of this is the case of poly(lactic acid), a biodegradable polymer made from the acid present in milk (lactic acid). Both the polymer and monomer are non-toxic but lactic acid, as its name suggests, is an acid and changes the acidity $(\mathrm{pH})$ of its surrounding. If a lot of this polymer were to accumulate in the environment and degrade, the $\mathrm{pH}$ change caused by lactic acid may have profound and unpredicted effects on the local environment. This is just one example of the importance of the degradation products and the full understanding of the degradation 
pathways. Without such understanding, such polymers may degrade but cause significant environmental damage further down the line.

A further point to consider is that degradation of materials releases energy - take your garden compost heating up as an example. This energy comes from the break-down of chemical linkages within the polymer, and in the case of degradation is usually lost to the surrounding environment. However, this energy could be transformed into electricity in a waste incineration plant, as is currently done for much of our plastic waste. Evidently, this is only advantageous from an environmental standpoint if the plastic is made from renewable resources and energy and thus does not release any additional $\mathrm{CO}_{2}$ during its incineration.

Despite the above points, (bio)degradable polymers can still be extremely useful and powerful for certain applications. One particularly successful use of such polymers has been in the biomedical field as sutures for wounds. In this case, the degradation is an added functionality, eliminating the need to remove the stitches because they just degrade over time and making the process more comfortable for the patient and less time-intensive for the medical team. Overall, (bio)degradable polymers are extremely suitable for specific applications in which the degradation is an added function of the polymer, but the mass use of degradable polymers is most likely not advantageous from a sustainability point of view.

\section{6 - Pathways to More Sustainable Polymers}

All the above points were looking at the big picture of plastics within our society. This very complex problem of a circular approach to plastic production, use, reuse, recycling and upcycling will only be possible to tackle by uniting all involved disciplines, ranging from product design, engineering, and chemistry to waste management. This section focuses on the chemical aspects of what fundamentally can be done to improve the sustainability of polymers in general.

Most people will argue that chemistry is smelly, bad for your health, and dangerous to the environment, and until the 1990s this was probably very true. Stories of scientists washing their hands with benzene, a now largely banned carcinogenic and toxic chemical, are still told by professors to first-year students. With an increasing awareness of the short- and long-term health and environmental effects of certain chemicals, a new discipline called green and sustainable chemistry has evolved [22]. The fundamental concept of this branch of chemistry is simple: make chemistry safe, efficient, and environmentally-friendly while using resources available renewably and in abundance in nature. The fundamental twelve principles of Green 
Chemistry were first outlined by Paul Anastas and John Warner in 1998 [23] and highlight various aspects of chemistry to be considered (Figure 3). These green chemistry concepts go hand in hand with sustainability and the two are often used interchangeably. However, there is a fundamental difference between the two. While a chemical or a reaction can simply tick the different aspects of green chemistry, sustainability is not a characteristic itself but always a comparison to something else. This makes the claim "something is sustainable" much trickier and clearly defined criteria are currently not universally used. The ideal scenario would be to perform a Life Cycle Assessment (as mentioned above) for each product and compare it to other existing pathways in terms of environmental impact. However, such analyses take a long time and require huge amounts of data on each step of the production. These are most often not easily available for new synthetic schemes performed in a research laboratory, making this very detailed assessment impractical. As a result, other, simpler indicators for the sustainability of a chemical reaction are typically used, such as toxicity of substances, waste generated, and energy used. The toxicity of substances can be easily found on the European Chemicals Agency (ECHA) database with detailed information on human, aquatic, and other toxicities [24]. Using this database, the "greenest" and most sustainable pathway in terms of using the least number of toxic chemicals can be selected. A further useful metric is that of the Environmental factor, or E-factor. It was first proposed by Roger Sheldon in the early 90s [25] and determines the amount of chemical waste for each kilogram of product generated:

$$
E \text { factor }(\mathrm{kg} / \mathrm{kg})=\frac{\text { chemicals used }(\mathrm{kg})-\operatorname{product}(\mathrm{kg})}{\text { product }(\mathrm{kg})}
$$

This calculation includes all solvents, reagents, catalysts, filter media, and other chemicals needed to obtain the specific product and is thus an easy to calculate a comparable metric between different synthetic strategies. The only drawback is that these numbers need to be freely accessible. While this is not a problem for reactions you have run yourself, previous publications and commercially available chemicals do not come with all of this information.

Therefore, E-factor calculations typically start at commercially available chemicals, which sometimes leaves out a vast amount of waste generated to obtain these chemicals.

One of the most important pieces of information, apart from toxicity and waste, is the amount of energy needed to obtain a product. A chemical process may use no toxic substances and generate very little waste, but if the production requires energy to heat it to $400{ }^{\circ} \mathrm{C}$ rather than room temperature, then the overall environmental impact generated will still be significant. The measurement of how much energy a process uses is well established in industry for largescale instrumentation. The small-scale reactions and processes typically used in a laboratory, 
however, are much harder to evaluate in terms of energy consumption. A further complication is the difference in the electricity production from country to country. While Switzerland, for example, draws most of its energy (97\%) from low- $\mathrm{CO}_{2}$ sources such as hydropower and nuclear plants [26], Germany still relies heavily (44\%) on the burning of fossil fuels [27]. This has huge implications on the energetic environmental impact for each country and a comparison between countries is not always possible.

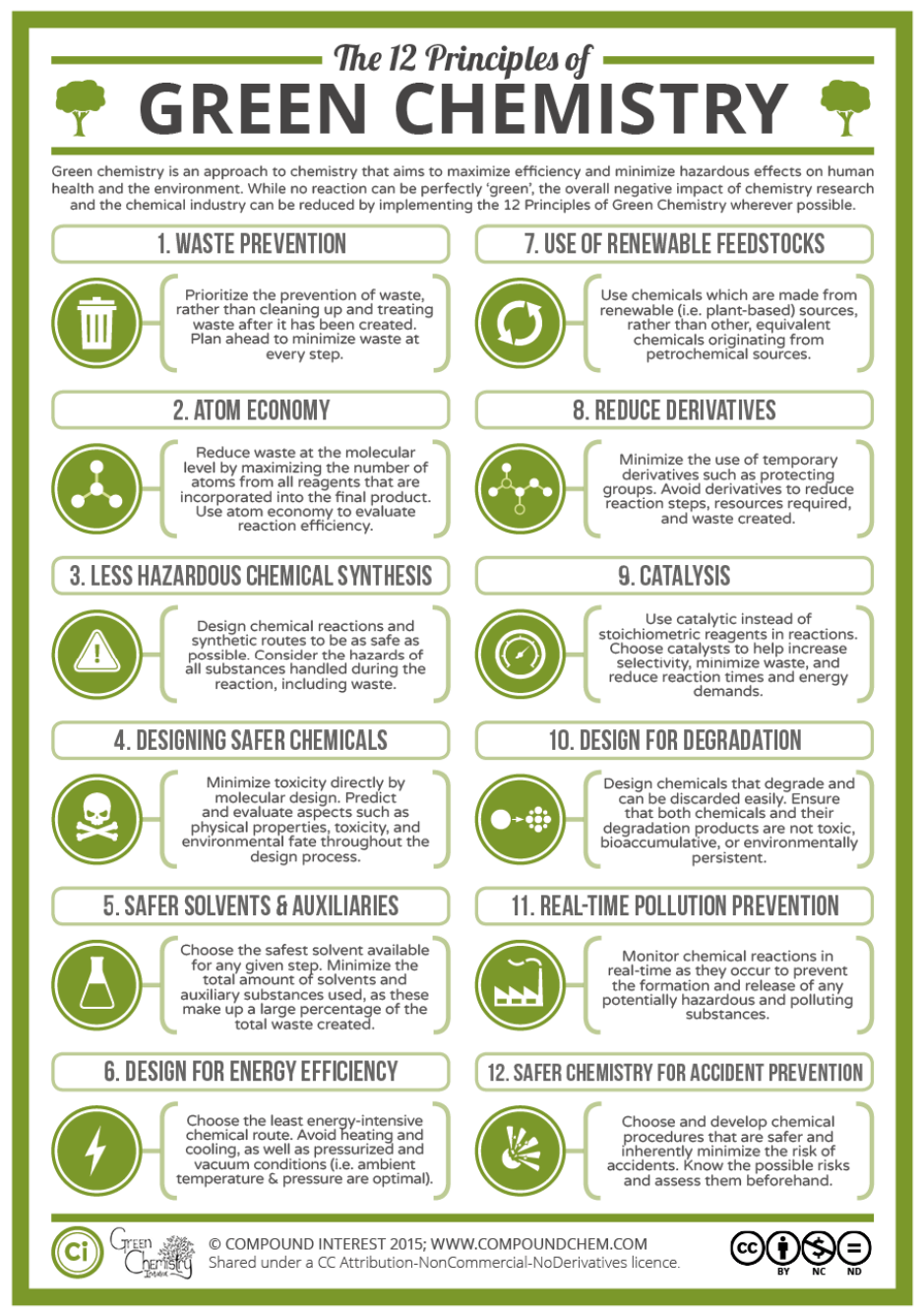

Figure 3: The twelve principles of Green chemistry with an explanation of each principle. Image taken from CompoundChem [28].

Overall, making polymers (or any product) more sustainable is a very complex task with many different aspects to consider. While the green chemistry principles provide basic guidelines, the actual sustainability of a chemical needs to be closely assessed with measurable tools and compared to an existing standard. Both of these are often complex and time-consuming tasks, but give a valuable and quantitative assessment of the environmental 
impact. The rapid growth of green chemistry over the last thirty years and the continuous development of analytical methods for sustainability have greatly advanced the move towards more sustainable polymers.

\section{7 - Conclusion}

In conclusion, polymers are extremely useful and cannot be replaced for most applications. The current spotlight plastics are facing is less an issue with the material itself but rather its linear and often singular use as well as its poor recyclability and degradability. Current efforts towards a more circular use of resources are leading the way towards a more sustainable use of this valuable material. Overall, the joint effects of scientific investment, legislation, and a change in people's perception of plastic will ensure that we arrive at a more sustainable and green future.

\section{8 - Acknowledgements}

The European Union is acknowledged for continuous support through the Horizon 2020 programme, currently the Marie Curie Individual Fellowship "DECOMPOSE" (grant no. 887935). The author thanks Patricia N. Johnson for her critical reading of this manuscript.

\section{9 - References}

[1] Staudinger, H. Über Polymerisation. Berichte der Dtsch. Chem. Gesellschaft (A B Ser. 1920, 53 (6), 1073-1085, DOI 10.1002/cber.19200530627.

[2] NobelPrize.org. Hermann Staudinger - Biographical https://www.nobelprize.org/prizes/chemistry/1953/staudinger/biographical/ (accessed Aug 31, 2020).

[3] Université de Liège. [MT180] Le joailler du plastique - Philip Scholten https://www.youtube.com/watch?v=Ef-Gco615SY

[4] Barlow, C. Y.; Morgan, D. C. Polymer Film Packaging for Food: An Environmental Assessment. Resour. Conserv. Recycl. 2013, 78, 74-80,

DOI: https://doi.org/10.1016/j.resconrec.2013.07.0033

[5] Edwards, C.; Fry, J. M. Life Cycle Assessment of Supermarket Carrier Bags: A Review of the Bags Available in 2006; 2011, DOI 10.1016/S1011-1344(98)00196-1.

[6] Curran, M. A. Life Cycle Assessment: A Review of the Methodology and Its Application to Sustainability. Curr. Opin. Chem. Eng. 2013, 2 (3), 273-277,

DOI: https://doi.org/10.1016/j.coche.2013.02.002 . 
[7] Bitesize BBC. Ways of reducing the use of resources - AQA https://www.bbc.co.uk/bitesize/guides/zwvq4qt/revision/1 (accessed Sep 14, 2020).

[8] Ellen MacArthur Foundation. Concept: What is a circular economy? https://www.ellenmacarthurfoundation.org/circular-economy/concept (accessed Sep 14, 2020).

[9] Stahel, Walter, R.; Reday-Mulvey, G. Jobs for Tomorrow, the Potential for Substituting Manpower for Energy; Vantage Press, 1981.

[10] Ritchie, H. Plastic Pollution https://ourworldindata.org/plastic-pollution (accessed Sep 15, 2020).

[11] Baldé, C. P.; Forti, V.; Gray, V.; Kuehr, R.; Stegmann, P. The Global E-Waste Monitor 2017 - Quantities, Flows, and Resources; United Nations (UNU), International Telecommunication Union (ITU) \& International Solid Waste Association (ISWA), Bonn/Geneva/Vienna, 2017.

[12] European Topic Centre on Waste and Materials in a Green Economy, E.; European Environment Agency, E. The role of circular business models, policy options, education and behavioural change in circular textiles systems https://www.eea.europa.eu/themes/waste/resourceefficiency/textiles-in-europe-s-circular-economy

(accessed Sep 15, 2020).

[13] Nunez, C. What is global warming, explained https://www.nationalgeographic.com/environment/global-warming/global-warming-overview/ (accessed Sep 15, 2020).

[14] Nunez, C. Fossil fuels, explained https://www.nationalgeographic.com/environment/energy/reference/fossil-fuels/ (accessed Sep 15, 2020).

[15] European Commission. Study on the Review of the List of Critical Raw Materials. Critical Raw Materials Factsheets; 2017, DOI 10.2873/876644.

[16] European Commision. An EU Action Plan for the Circular Economy; 2015.

[17] United Nations. Transforming our world: the 2030 Agenda for Sustainable Development https://sdgs.un.org/2030agenda (accessed Sep 15, 2020)

[18] ICIS; Petcore. ICIS and Petcore Europe PET Recycling Survey 2017 https://www.petcore-europe.org/news-events/202-2017-survey-on-european-pet-recycleindustry-58-2-of-pet-bottles-collected.html (accessed Sep 14, 2020).

[19] Rahimi, A.; García, J. M. Chemical Recycling of Waste Plastics for New Materials Production. Nat. Rev. Chem. 2017, 1 (6), 46, DOI 10.1038/s41570-017-0046.

[20] Hong, M.; Chen, E. Y.-X. Chemically Recyclable Polymers: A Circular Economy Approach to Sustainability. Green Chem. 2017, 19 (16), 3692-3706, DOI 10.1039/C7GC01496A.

[21] American Chemistry Council. Plastics - What is Advanced Recycling? https://plastics.americanchemistry.com/what-is-advanced-recycling/ (accessed Sep 14, 2020).

[22] American Chemcial Society. What is Green Chemistry? https://www.acs.org/content/acs/en/greenchemistry/what-is-green-chemistry.html (accessed Sep 14, 2020). 
Bulletin de la Société Royale des Sciences de Liège, Vol. 90, Articles, 2021, p. 17 - 29

[23] Anastas, P. T.; Warner, J. C. Green Chemistry: Theory and Practice; Oxford University Press, 1998.

[24] European Union. European Chemicals Agency, https://echa.europa.eu/home (accessed Mar 20, 2020).

[25] Sheldon, R. A. The: E Factor 25 Years on: The Rise of Green Chemistry and Sustainability. Green Chem. 2017, 19 (1), 18-43, DOI 10.1039/c6gc02157c.

[26] Federal Department of Foreign Affairs. Energy - Facts and Figures

https://www.eda.admin.ch/aboutswitzerland/en/home/wirtschaft/energie/energie---fakten-und-

zahlen.html

(accessed Sep 15, 2020).

[27] Umweltbundesamt. Stromerzeugung erneuerbar und konventionell

https://www.umweltbundesamt.de/daten/energie/stromerzeugung-erneuerbar-

konventionell\#stromerzeugung-nach-energietragern-

(accessed Sep 15, 2020).

[28] Compound Interest. The Twelve Principles of Green Chemistry: What it is, \& Why it Matters https://www.compoundchem.com/2015/09/24/green-chemistry/

(accessed Sep 15, 2020). 